\title{
An Initial Investigation of an Alternative Model to Study rat Primordial Germ Cell Epigenetic Reprogramming
}

\author{
Isabelle Hernandez Cantão $0^{1,2}$, Renato Borges Tesser ${ }^{1,2}$ and Taiza Stumpp ${ }^{1,2^{*}}$ (D)
}

\begin{abstract}
Background: Primordial germ cells (PGC) are the precursors of the gametes. During pre-natal development, PGC undergo an epigenetic reprogramming when bulk DNA demethylation occurs and is followed by sex-specific de novo methylation. The de novo methylation and the maintenance of the methylation patterns depend on DNA methyltransferases (DNMTs). PGC reprogramming has been widely studied in mice but not in rats. We have previously shown that the rat might be an interesting model to study germ cell development. In face of the difficulties of getting enough PGC for molecular studies, the aim of this study was to propose an alternative method to study rat PGC DNA methylation. Rat embryos were collected at 14, 15 and 19 days post-coitus (dpc) for the analysis of 5mC, 5hmC, DNMT1, DNMT3a and DNMT3b expression or at 16dpc for treatment 5-Aza-CdR, a DNMT inhibitor, in vitro.

Methods: Once collected, the gonads were placed in 24-well plates previously containing $45 \mu \mathrm{m}$ pore membrane and medium with or without 5-Aza-CdR. The culture was kept for five days and medium was changed daily. The gonads were either fixed or submitted to RNA extraction.

Results: $5 \mathrm{mC}$ and DNMTs labelling suggests that PGC are undergoing epigenetic reprogramming around 14/15dpc. The in vitro treatment of rat embryonic gonads with $1 \mu \mathrm{M}$ of 5-Aza-CdR lead to a loss of $5 \mathrm{mC}$ labelling and to the activation of Pax6 expression in PGC, but not in somatic cells, suggesting that 5-Aza-CdR promoted a PGC-specific global DNA hypomethylation.

Conclusions: This study suggests that the protocol used here can be a potential method to study the wide DNA demethylation that takes place during PGC reprogramming.
\end{abstract}

Keywords: Rat, Primordial germ cell, Epigenetic reprogramming

\section{Background}

Primordial germ cells $(\mathrm{PGC})$ are peculiar cells that differentiate into gametes and transmit the genetic and epigenetic information to the next generations. In mice, PGC arise from a pool of epiblastic cells that retain the expression of pluripotent markers [1-3]. This pool of cells starts to express fragillis and Blimp1, which conduce to a germ cell fate [4-7]. PGC then migrates via the hindgut and its mesentery to reach the genital ridges, where they undergo male or female differentiation.

\footnotetext{
* Correspondence: taiza.stumpp@gmail.com

${ }^{1}$ Laboratory of Developmental Biology, Department of Morphology and Genetics, Federal University of Sao Paulo (UNIFESP), Sao Paulo, Brazil

${ }^{2}$ Rua Botucatu, 740. Ed. Leitão da Cunha, 20 andar. CEP: 04023-900, São Paulo, Brazil
}

The switch from a somatic to a germ cell program depends initially on the maintenance of pluripotency markers and later on epigenetic reprogramming, when PGC DNA is widely hypomethylated [8-10] and then de novo hypermethylated in a sex-specific manner [11]. Mouse PGC reprogramming starts around $8 \mathrm{dpc}$ and ends around $16.5 \mathrm{dpc}$ in males, when DNA de novo methylation ends $[4,8,10-15]$. De novo DNA methylation, as well as the maintenance of methylation patterns during cell division, occur via DNA methyltransferases MT). DNMT3a and DNMT3b are described as de DNA methyltransferases capable of establishing methylation patterns whereas DNMT1 is considered the maintenance DNMT during DNA replication. 
It has been suggested that DNA demethylation in mouse PGC occurs through two mechanisms: oxidation of $5 \mathrm{mC}$ to $5 \mathrm{hmC}$ via TET enzymes and through replication-dependent dilution [16, 17]. These mechanisms operate in three steps: the first is a passive process of replicative-dilution of $5 \mathrm{mC}$ possibly due to a lack of DNMT1 function and occurs from $8.5 \mathrm{dpc}$ to $9.5 \mathrm{dpc}$; the second is the active process where $5 \mathrm{mC}$ are oxidated to $5 \mathrm{hmC}$ via TET (Ten-eleven translocation) enzymes at $10.5 \mathrm{dpc}$; and the third step is again a passive step that consists in the replicative-dilution of $5 \mathrm{hmC}$ from $10.5 \mathrm{dpc}$ to $13.5 \mathrm{dpc}$ [17].

Like in the early embryo, the de novo DNA methylation as well as the maintenance of DNA methylation also seems to be mediated by the DNMTs, although the data are controversial. DNMT1 seems to be dispensable for the reacquisition of DNA methylation in male germ cells $[18,19]$. On the other hand, DNMT3a is responsible for de novo DNA methylation $[18,20]$, whereas DNMT3b would function in the maintenance of de novo DNA methylation [20] or would not be required in prenatal germ cell development [18].

The natural epigenetic reprogramming by which germ cells go through is one of the most interesting events of their pre-natal development. Although the meaning of this event has not been clarified, it is likely to be related to the establishment of a totipotent state that seems to be fundamental for germ cell differentiation [21] and maybe to confer the developmental potential to the future gametes. Investigations about the role of DNA methylation in gene expression have made use of agents that impair the maintenance of DNA methylation, such as 5-Azadeoxycitidine (5-Aza-CdR), to induce artificial DNA demethylation in vitro [12, 22]. 5-Aza-CdR is known to interact with DNMT1, inhibiting its activity. This compound acts in both proliferating and nonproliferating cells $[23,24]$ and is able to activate genes which expression is controlled by promoter methylation [12, 22].

Although the mouse has been the main model for studies on germ cell development, we have previously shown relevant differences in the detection of germ cell markers between mice and rats [25], suggesting that the rat also seems to be an important model to study germ cell development. Despite the relatively abundant studies about PGC reprogramming, especially in the mouse, the methodologies involved are laborious due to the low number of PGC in the initial phases of their development. When the rat is the model of choice, the difficulties are increased due to the fact that less information and tools are available for this species.
In face of the technical difficulties to study the control of gene expression by DNA methylation in PGC coupled to the impossibility to establish PGC cultures that maintain their in vivo characteristics, we aimed to find new and simpler methodologies to study the mechanisms involved in DNA methylation and demethylation in rat PGC. Here we describe DNMT expression in rat embryo gonads and a method that lead to the specific hypomethylation of PGC DNA by the DNMT inhibitor 5-Aza-CdR. This study may be useful for future investigations in the field.

\section{Results}

Dnmt Expression and Selection of the age for 5-Aza-CdR Treatment

Considering that 5-Aza-CdR acts through the inhibition of DNMT1 activity [26], the presence of this enzyme was investigated in rat PGC (Figs. 1 and 2). DNMT1, which is responsible for maintaining DNA methylation (DNMT1), was not detected in PGC at 14dpc in both protein (Fig. 1a) and RNA (Fig. 2) levels, suggesting that DNMT1 activity is not necessary in PGC at this stage of rat germ cell development. On the other hand, at $15 \mathrm{dpc}$ (Fig. 1b) and at 19dpc (Fig. 1c) DNMT1 was detected in PGC at protein level, although at $19 \mathrm{dpc}$ its expression at RNA level could be barely detected (Fig. 2).

Because DNMT1 was absent in PGC at 14dpc but was detected at $15 \mathrm{dpc}$, we hypothesized that this might represent a moment when PGC DNA is globally remethylated. The de novo DNA methylation depends on the activity of the de novo DNA-methyltransferases DNMT3a and DNMT3b $[27,28]$. Thus, we looked at the expression of these enzymes in the rat PGC. As expected, DNMT3a was not detected at $14 \mathrm{dpc}$ in protein (Fig. 1d) or RNA level (Fig. 2). Interestingly, DNMT3a labelling was not detected on PGC of in 15dpc embryos at protein level (Fig. 1e) but was detected at the RNA level (Fig. 2). Similarly, this enzyme was detected in 19dpc germ cells, now called gonocytes, at protein level (Fig. 1f), but not at the RNA level, (Fig. 2). DNMT3b immuno-labelling in rat PGC showed the opposite pattern from that observed for DNMT3a, although the pattern of RNA expression was the same for both enzymes (Fig. 2). DNMT3b labelling was detected at $14 \mathrm{dpc}$ (Fig. 1g) and at 15dpc (Fig. 1h), although few negative PGC were observed, whereas at 19dpc (Fig. 1i) DNMT3b was not detected in germ cells. DNMT3a and DNMT3b expression at protein level suggests that these enzymes seem to act at distinct phases of rat germ cell development. On the other hand, at RNA level, these enzymes seem to have very similar expression pattern. The inequivalence between protein and RNA data might be a reflexion of technique sensitivity or might be a result of RNA metabolism. 


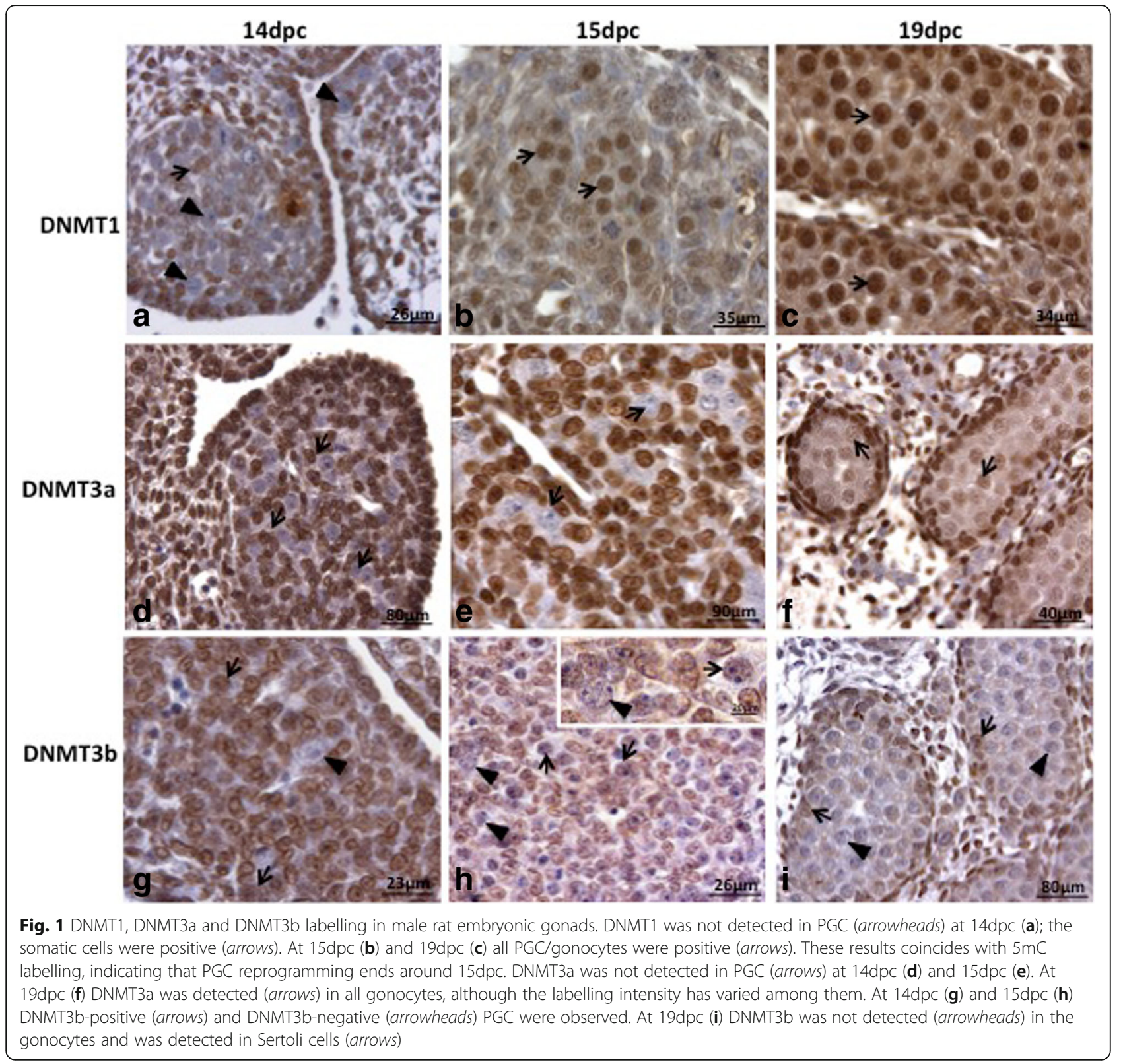

\section{$5 \mathrm{mC}$ and $5 \mathrm{hmC}$ Immunolabelling}

Because 5-Aza-CdR is expected to promote DNA demethylation through interaction with DNMT1, we investigated $5 \mathrm{mC}$ and $5 \mathrm{hmC}$ labelling in normal gonads as a basis for the analysis of 5-Aza-CdR effectiveness. $5 \mathrm{mC}$ was not detected at $14 \mathrm{dpc}$ (Fig. 3a) but appeared at 15dpc (Fig. 3b), when the presence of negative PGC was very rare. At 19dpc all PGC were positive for $5 \mathrm{mC}$ (Fig. 3c). These data are somewhat discordant with a recent study showing that rat PGC DNA is hypomethylated from 14.5-19.5dpc [29]. This discrepancy could be due to the different methodological approaches used, such as fixative solutions, which are essential for the detection of this epigenetic mark. 5-hydroxymethylcytosine $(5 \mathrm{hmC})$ is the product of $5 \mathrm{mC}$ oxidation by TET (Ten-eleven translocation) enzymes. During mouse PGC reprogramming, DNA demethylation depends on $5 \mathrm{mC}$ oxidation to $5 \mathrm{hmC}$ $[16,17]$. In the present study, $5 \mathrm{hmC}$ labelling was detected in a restricted area of PGC nucleus from at $14 \mathrm{dpc}$ and $15 \mathrm{dpc}$ (Figs. 3d and e). The labelling area showed a progressive reduction as the age increased, appearing very rarely at $15 \mathrm{dpc}$ until becoming undetectable at 19dpc (Fig. 3f). This agrees with recent data on rat PGC showing that $5 \mathrm{hmC}$ labelling is present between $14.5 \mathrm{dpc}$ and $16.5 \mathrm{dpc}$ but is absent at $19.5 \mathrm{dpc}$ [31]. 


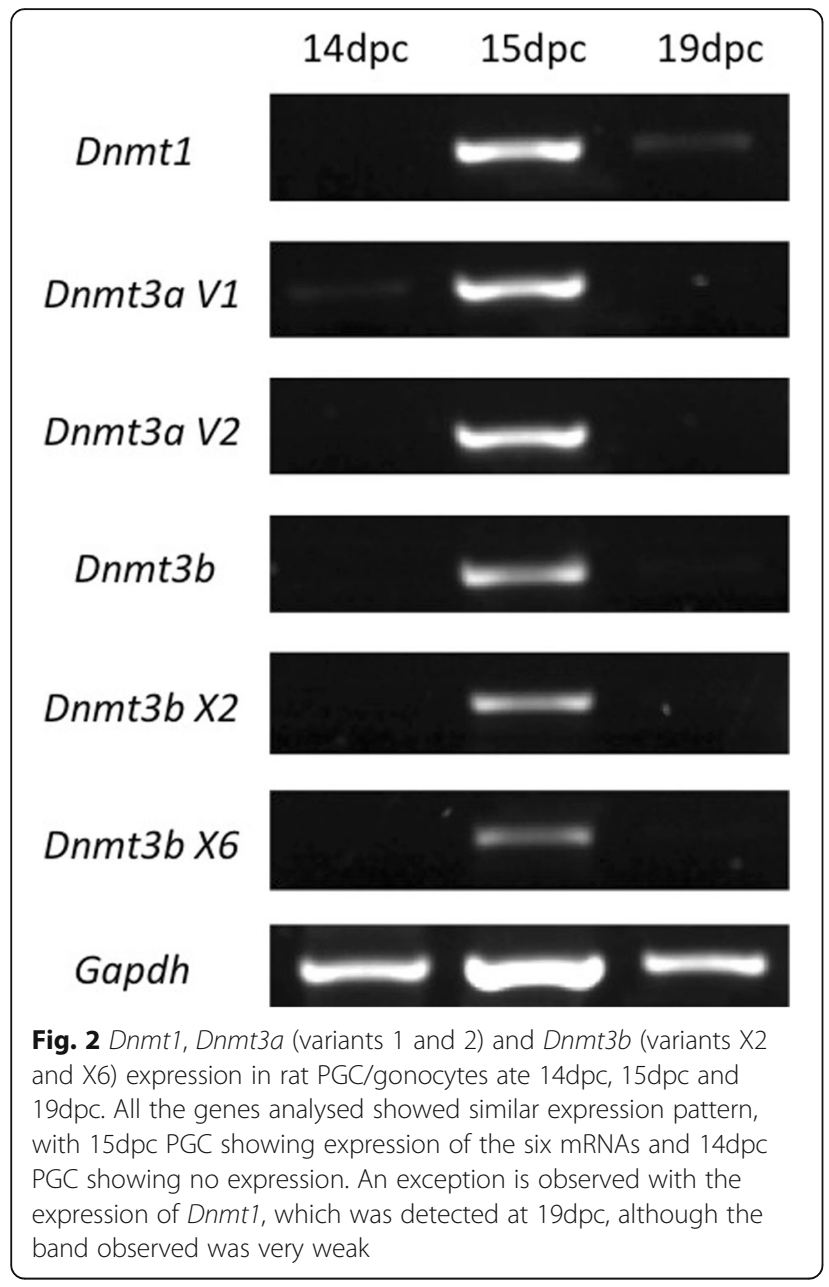

In Vitro 5-Aza-CdR Administration

The DNMT1 and $5 \mathrm{mC}$ data obtained here were used to choose the embryonic age for the in vitro studies using 5-Aza-CdR. Furthermore, we have previously shown that rat PGC migration ends between $15 \mathrm{dpc}$ and $16 \mathrm{dpc}$ [25]. These findings led us to choose the age of $16 \mathrm{dpc}$ for 5 Aza-CdR treatment.

Morphological analysis of the gonads (Fig. 4) and $5 \mathrm{mC}$ labelling (Fig. 5) were used to select the adequate dose of 5-Aza-CdR for the aims of this study. Non-cultured (C) (Fig. 4a) and culture-control (CC) (Fig. 4b) were used as basis for comparison of the 5-Aza-CdR-treated gonads. Three concentrations of 5 -Aza-CdR were used $(1 \mu \mathrm{M}, 3 \mu \mathrm{M}$ and $5 \mu \mathrm{M})$. The gonads treated with $1 \mu \mathrm{M}$ (Fig. 4c) showed well-preserved morphology when compared with $\mathrm{C}$ (Fig. 4a) and CC (Fig. 4b) gonads. The gonads treated with $3 \mu \mathrm{M}$ (Fig. $4 \mathrm{~d}$ ) and $5 \mu \mathrm{M}$ (Fig. $4 \mathrm{e}$ ) of 5 -Aza-CdR showed apparent reduction of its size and morphological alterations, such as cell degeneration (Fig. 4d). In the gonads treated with $5 \mu \mathrm{M}$ of 5 -AzaCdR PGC were rare and the gonads contained basically somatic cells (Fig. 4e).
5mC and 5hmC Labelling after 5-Aza-CdR Treatment

The gonads treated with $1 \mu \mathrm{M}$ and $3 \mu \mathrm{M}$ of 5 -Aza-CdR were submitted to $5 \mathrm{mC}$ immuno-labelling. The gonads treated with $5 \mu \mathrm{M}$ of 5 -Aza-CdR were excluded from this analysis due to the significant germ cell loss, as described above.

As observed for the $19 \mathrm{dpc}$ embryos, $5 \mathrm{mC}$ was detected in all PGC of the 16dpc embryos (Fig. 5a). After the incubation of embryonic male gonads without 5-Aza-CdR (CC), $5 \mathrm{mC}$ was also detected in all PGC and somatic cells (Figs. 5b). On the other hand, $5 \mathrm{mC}$ was barely detected in the PGC of the gonads incubated with $1 \mu \mathrm{M}$ of 5-Aza-CdR (Aza1), but was detected in the somatic cells (Fig. 5c), suggesting that the PGC are more sensitive to 5-Aza-CdR effect on DNA demethylation than the somatic cells. In the gonads treated with $3 \mu \mathrm{M}$ of 5 Aza-CdR (AzaC3) 5mC labelling was very reduced in both PCG and somatic cells (Fig. 5d), suggesting that this dose is able to induce the loss of $5 \mathrm{mC}$ not only in PGC DNA but also in somatic cell DNA. Therefore, we suggest that the dose of $1 \mu \mathrm{M}$ represents an suitable concentration of 5-Aza-CdR to perform studies involving $5 \mathrm{mC}$ detection in rat PGC in whole gonad culture systems.

In control embryo the gonads $(\mathrm{C}) 5 \mathrm{hmC}$ labelling was rarely observed and, when present, was restricted to a small area of PGC nucleus (Fig. 5e). Interestingly, both CC (Fig. 5f) and in AzaC1 (Fig. 5g) gonads showed 5hmC labelling in PGC and Sertoli cells, although it was more intense in Sertoli cells than in PGC. This suggests that the protocol of gonad culture used here leads to an increase of $5 \mathrm{hmC}$ detection in PGC.

\section{PGC Quantification and Proliferation}

Because the morphological analysis of the AzaC1 gonads suggested an increase of PGC number, we decided to count these cells using a germ cell marker (DAZL) associated with a proliferation marker (Ki67). The Ki67/DAZL double-labelling indicated that PGC proliferation was active in the $\mathrm{C}$ gonads (Figs. 6a to d), but was inactive in both $\mathrm{CC}$ (Figs. 6e to $\mathrm{h}$ ) and $\mathrm{AzaC} 1$ gonads (Figs. 6i to l). If germ cells continue to develop in vitro, it is indeed expected that their proliferation has ceased by the end of the culture period, when these cells would correspond to $20 \mathrm{dpc}$ germ cells. At this age rat male germ cells has entered mitotic arrest (Zogbi et al. [30]). The Ki67/Dazl double-labelling was then performed in 20dpc embryos to confirm this data. Indeed, no Ki67 labelling was observed in the 20dpc germ cells (Figs. $6 \mathrm{~m}$ to $\mathrm{p}$ ). Despite the fact that PGC were Ki67-negative by the end of the culture period, the number of PGC in the AzaC1 gonads was higher when compared with the control gonads (Table 1), 


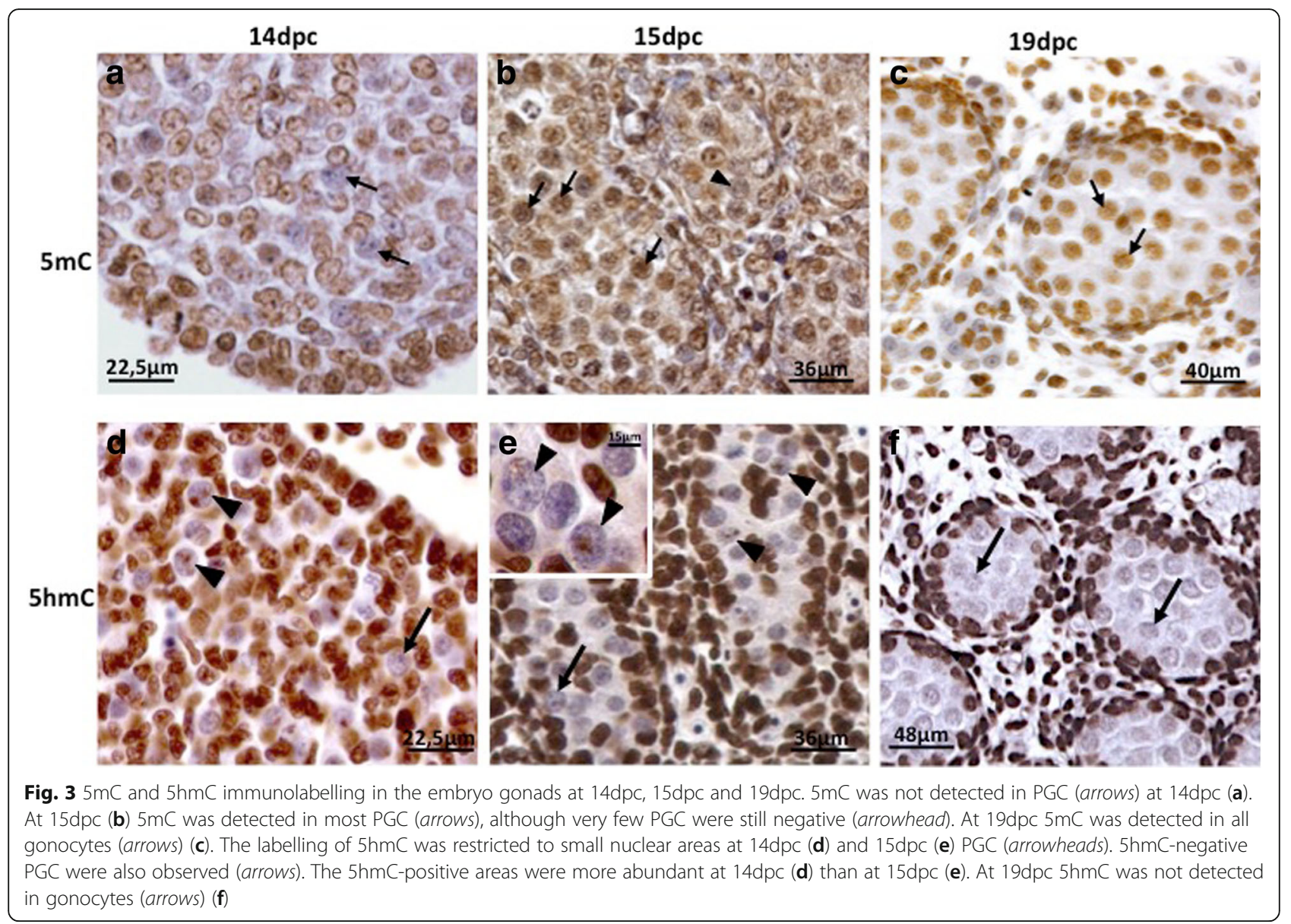

what lead to an increase of the numerical density $(\mathrm{Nv})$ of these cells in the AzaC1 gonads (Fig. 7). This suggests that 5-Aza-CdR caused an alteration of germ cell proliferation, although their maturation, which can be indicated by mitotic arrest, which was not impaired.

\section{Expression of Developmental Genes}

The expression of developmental genes is a mark of the early phases of embryo development and of embryonic stem cells. In mouse PGC these genes are not expressed, although seems to be maintained in a bivalent state [31, 32]. Since DNMTs are fundamental for the control of developmental genes expression during embryo development [33], we investigated whether 5-Aza-CdR treatment induces the expression of the somatic developmental gene Pax6 in rat PGC. Pax6 expression was not detected in the control (C and CC gonads) PGC or in the somatic cells. On the other hand, in the in the AzaC1 gonads Pax6 expression was detected in PGC but not in the somatic cells (Fig. 8), suggesting that the treatment with 5-AzaCdR induced PGC-specific activation of this gene.

\section{Discussion}

Germ cell development depends on strictly controlled events that assure their normal differentiation and consequently the production of functional gametes and healthy embryos. In this context PGC epigenetic reprogramming is of particular importance, since it is required for PGC sex differentiation, imprinting establishment and to provide adequate chromatin conditions for the future embryo development. Many important studies have been investigating and describing PGC epigenetic reprogramming, especially in the mouse, and have provided substantial data. However, studies about rat PGC epigenetics are very scarce, probably due to the reduced information about molecular aspects of the rat development when compared to mouse. This lead us to search for methodologies to study rat PGC epigenetics. Here we used 5-Aza-CdR, which is known to interact with DNMT1 and to block its activity, to promote male PGC DNA demethylation in vitro. To propose the protocol used here, we took into account two main aspects: the difficulties of getting enough number of PGC during early reprogramming and the fact that DNA methylation represents a major form of gene expression control. 

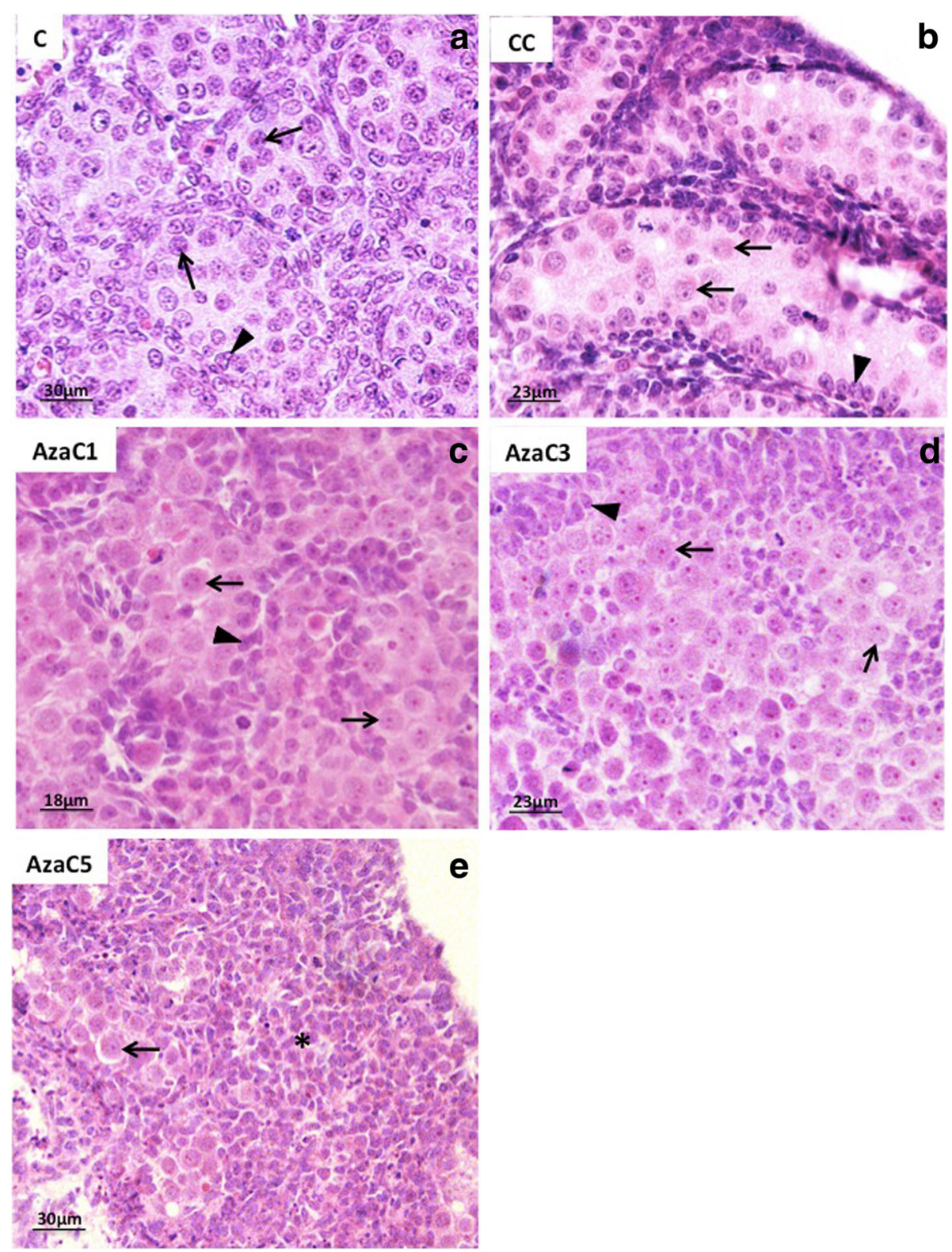

Fig. 4 Morphological analysis of the 16dpc gonads of control (C), culture-control (CC) and 5-Aza-CdR-treated gonads. In the C (a) and CC (b) gonads the seminiferous cords can be clearly distinguished. In the gonads treated with $1 \mu \mathrm{M}$ fo $5-A z a-C d R(A z a C 1 ; \mathbf{c})$ it still possible to note the cordonal organization, which is less evident in the gonads treated with $3 \mu \mathrm{M}$ of 5-Aza-CdR (AzaC3; d). The gonads treated with $5 \mu \mathrm{M}$ of 5-Aza-CdR (AzaC5; e) very few PGC are observed (arrow) and most of the gonad consisted of somatic cells $(*$ )

PGC reprogramming seems to involve the reduction of the activity of DNMT1 in the beginning of the reprogramming period $[13,34]$ followed by the recruiting of DNMT3a and DNMT3b $[18,35,36]$. Since 5-Aza-CdR inhibits DNMT1 activity and also affects DNMT3a and DNMT3b $[37,38]$, it was necessary to investigate the expression of these enzymes prior to establish the protocol of 5-Aza-CdR treatment in the rat gonad cultures. We detected DNMT1 in rat PGC at $15 \mathrm{dpc}$ and $19 \mathrm{dpc}$, but not at $14 \mathrm{dpc}$. Since DNMT1 is described as the maintenance DNMT, it is expected that its presence correlates with the moment of PGC de novo DNA methylation. However, a previous study showing epigenetic marks in rat PGC indicated that $5 \mathrm{mC}$ reestablishment occurs around 19.5dpc [39], suggesting DNA de novo methylation occurs in late gestational period. On the other hand, in mouse PGC, DNMT1 was detected between $12.5 \mathrm{dpc}$ and $16.5 \mathrm{dpc}$ [19], when DNA is globally demethylated [13], what agrees with our data. Conversely, [18] suggested that DNMT1 is not present in mouse PGC between $14.5 \mathrm{dpc}$ and $18.5 \mathrm{dpc}$, a period that includes demethylated and de novo 


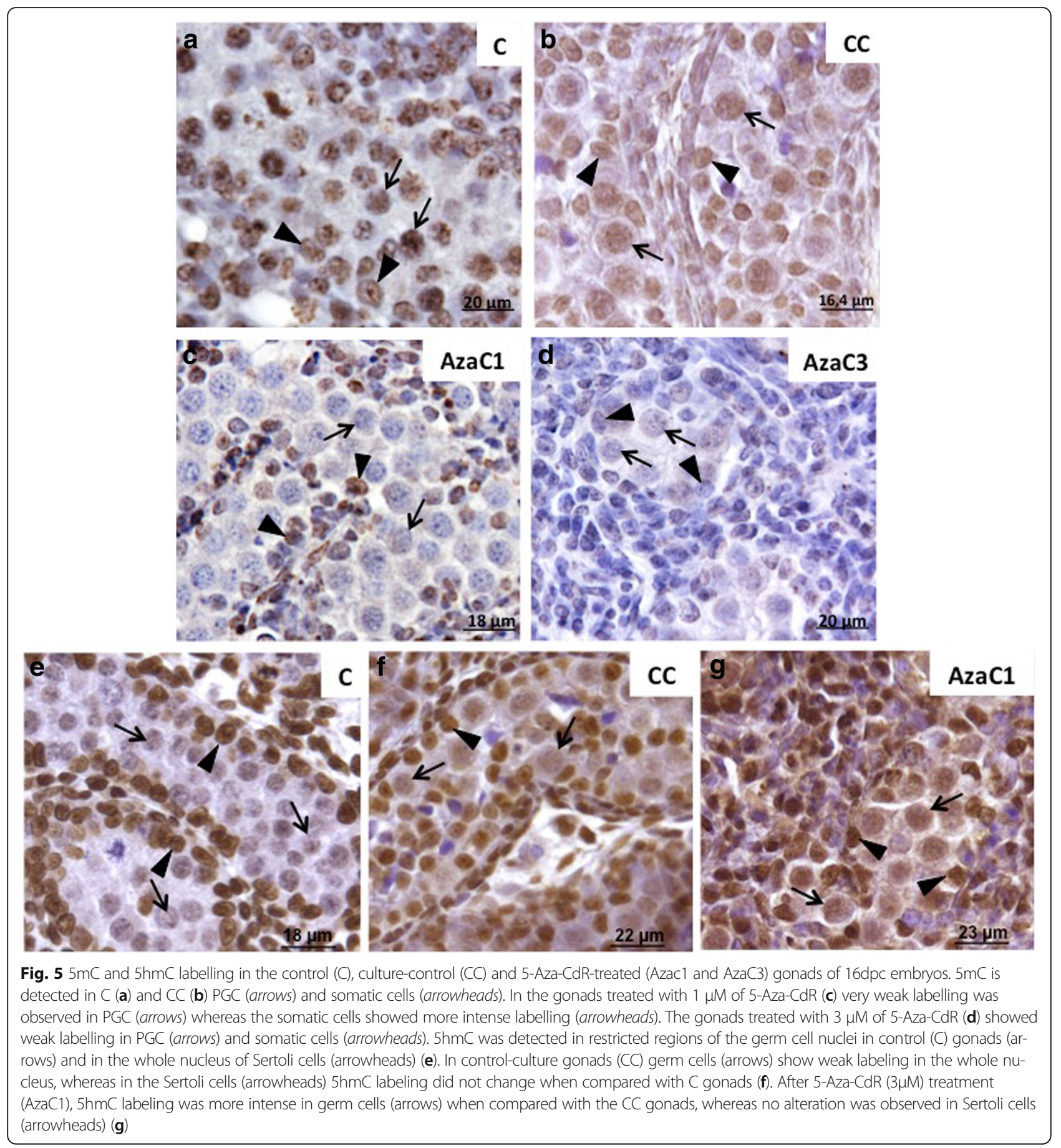

methylated DNA [13]. DNMT1 expression agrees with $5 \mathrm{mC}$ labelling, which was not detected at $14 \mathrm{dpc}$ and was detected at $15 \mathrm{dpc}$ and $19 \mathrm{dpc}$. These data suggest that rat PGC are hypomethylated at $14 \mathrm{dpc}$ and that de novo methylation may start between $14 \mathrm{dpc}$ and $15 \mathrm{dpc}$.

The de novo methyltransferases DNMT3a and DNMT3b are fundamental for de novo methylation of the mouse embryo [29] and ES cells [40] although seems to be dispensable for somatic cell nuclear reprogramming to a pluripotent state [41]. In the mouse germ cells DNMT3a, DNMT3b and DNMT3l are important for de novo methylation of imprinted regions during development and after birth and for retrotransposons silencing [42]. DNMT3a was reported to act in the acquisition of de novo methylation in mouse PGC $[18,20]$, whereas DNMT3b seems to function in the maintenance of methylation [20] 


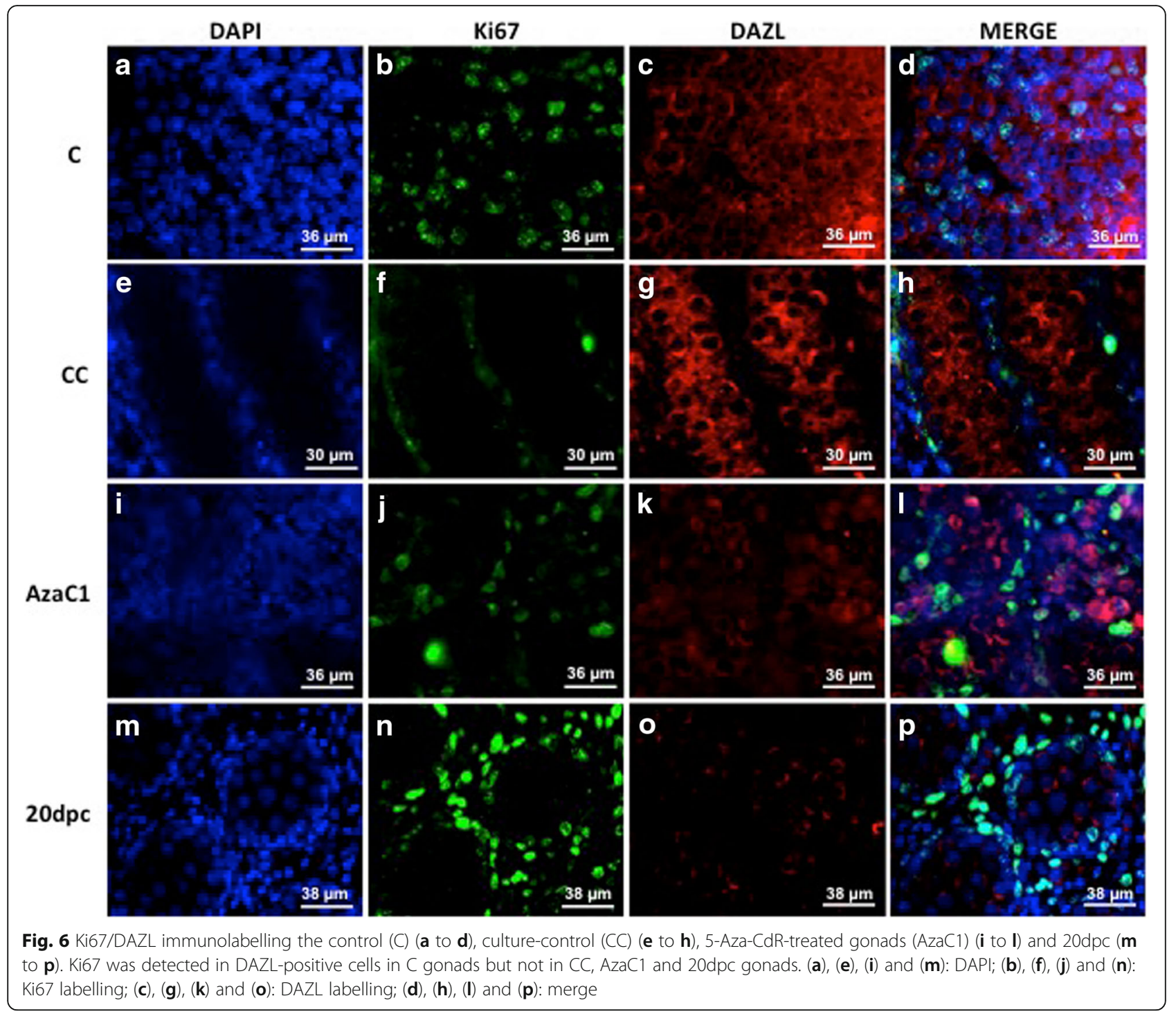

and to play a major role in the postnatal development of male germ cells [18]. Our data on DNMT3a expression suggest that this enzyme is not present in PGC at $14 \mathrm{dpc}$, what agrees with the $5 \mathrm{mC}$ data. However, at $15 \mathrm{dpc}$ and $19 \mathrm{dpc}$ the expression of this enzyme at both protein and RNA level is controversial, indicating that further studies are needed. In contrast DNMT3b was detected at $14 \mathrm{dpc}$ and $15 \mathrm{dpc}$ but not at $20 \mathrm{dpc}$, showing an opposite pattern to that

Table 1 Area and primordial germ cell count (N) averages in CC and AzaC1 groups

\begin{tabular}{lll}
\hline & CC & AzaC1 \\
\hline Area & $238,9 \pm 7,0$ & $256,8 \pm 6,7$ \\
N(PGC) & $149,8 \pm 7,4$ & $273,5 \pm 16^{*}$ \\
\hline
\end{tabular}

The gonad area was not different between $\mathrm{CC}$ and AzaC1 groups. However, the number of PGC was higher in AzaC1 gonads compared with CC gonads ${ }^{*} p<0.05$ observed for DNMT3a. This suggests that these de novo DNA-methyltransferases seem to play distinct roles in rat germ cell development.

PGC reprogramming in mice seems to be associated with changes in the expression of the DNMTs and their partners. The downregulation of Uhrf1, which is essential for DNMT1 activity, was observed in mice PGC in the beginning of epigenetic reprogramming [43], suggesting that DNMT1 action needs to be annulled at this stage of germ cell development. Thus, the use of a DNMT1 inhibitor seems to be a reasonable way to mimic, at least in part, the global DNA demethylation that occurs during PGC reprogramming. Our analyses suggest that the incubation of rat embryonic gonads with the DNMT1 inhibitor 5Aza-CdR was able to induce wide loss of $5 \mathrm{mC}$ in PGC DNA, without causing major global loss of this mark in somatic cells, as suggested by $5 \mathrm{mC}$ immno-labelling. The detection of Pax6 expression, which is controlled by 


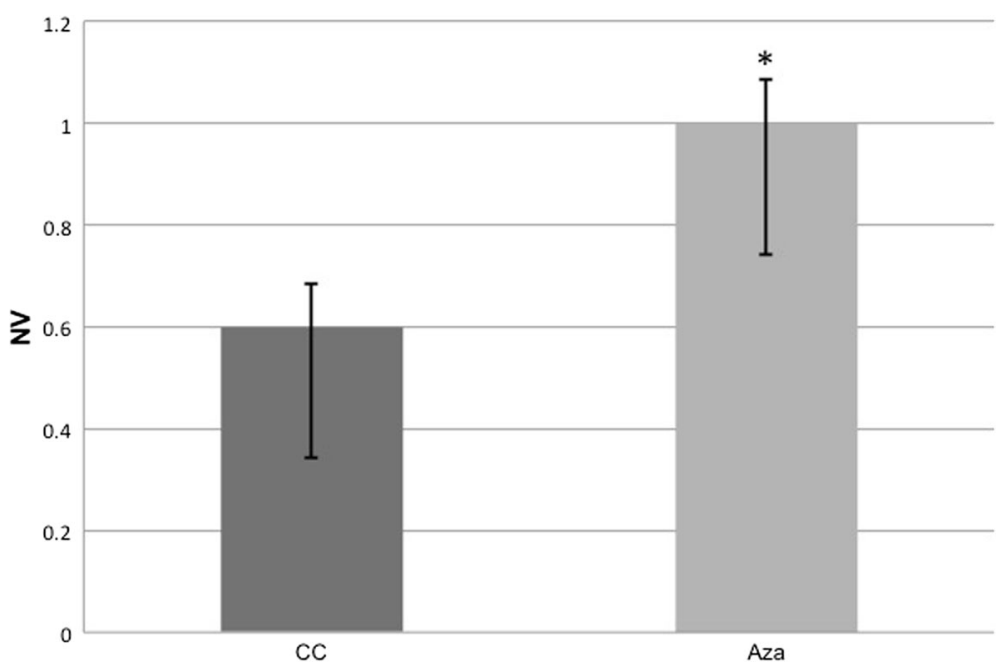

Fig. 7 PGC quantification in 16dpc culture-control (CC) and Aza-treated (Aza) embryo gonads. An increase in the numerical density (Nv) of PGC is observed in the Aza-treated gonads

promoter methylation [44], observed in PGC but not in the somatic cells of the gonads treated with 5 -Aza-CdR on in the control PGC corroborate to the hypothesis that 5-Aza-CdR treatment acted primarily on PGC. This suggests that in vitro treatment of whole-gonad with 5-Aza$\mathrm{CdR}$ might be an interesting method to study the control of gene expression by DNA methylation in PGC.

Considering that 5 -Aza-CdR is an inhibitor of DNMT1 activity, further studies investigating the pluripotency of PGC after 5-Aza-CdR treatment seems to be another point to be considered, since it has been shown that the absence of DNMTs leads to spontaneous pluripotency [45].

On the other hand, the alteration of $5 \mathrm{hmC}$ labelling even in the control culture gonads indicates that the culture method by itself is able to induce epigenetic changes in PGC. This and other aspects of PGC epigenetics, such as histone mark profile, need to be further

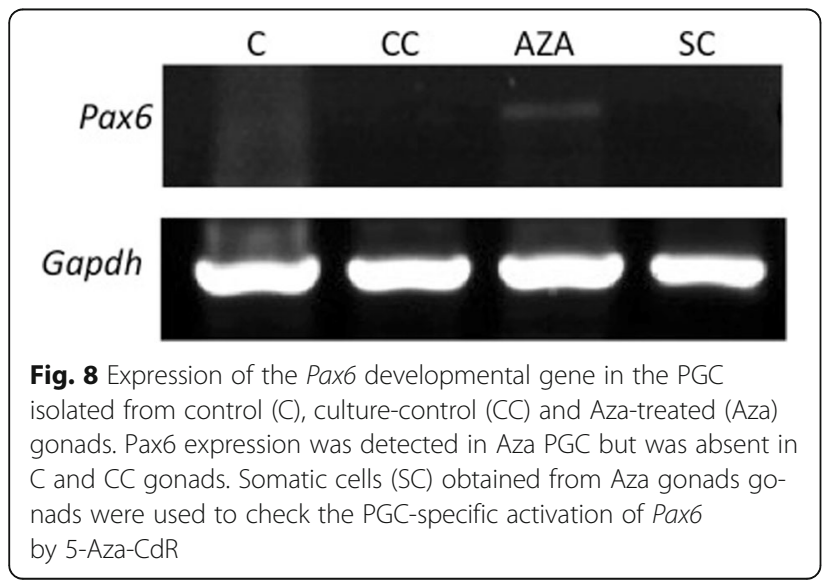

investigated to confirm whether this model would indeed be useful to study PGC epigenetics.

\section{Conclusion}

In conclusion, we describe the immuno-labelling of DNMTs in rat PGC and suggest that the administration of 5-Aza-CdR to rat gonads in vitro leads to a wide demethylation of PGC DNA without major effects on somatic cells. We finally suggest that this method might be a potential alternative method to study DNA methylation and demethylation, although additional studies are necessary to validate it.

\section{Methods}

\section{Animals and Tissue Preparation}

Male embryos were obtained from timed matings of adult Wistar rats (Rattus norvegicus albinus) from the Laboratory of Developmental Biology (EPM/UNIFESP, Sao Paulo - Brazil). The adult animals were kept in plastic cages under a $12-12 \mathrm{~h} \mathrm{light/dark}$ cycle at $23-25{ }^{\circ} \mathrm{C}$. Food and water were allowed ad libitum. The dams were anesthetized using the method of anaesthesia/analgesia (xylazin/ketamine, $10 \mathrm{mg} / \mathrm{Kg}$ and $100 \mathrm{mg} / \mathrm{Kg}$, respectively) and euthanized by cardiac incision. The embryos were collected at 14, 15, 16 and 19dpc. At $14 \mathrm{dpc}$ the rat embryos do not show sexual dimorphism. At 15, 16 and $19 \mathrm{dpc}$ sexing was performed by morphological inspection of the gonads and only male gonads were used. The gonads of 14, 15 and 19dpc embryos were fixed in Bouin's solution for $6 \mathrm{~h}$ or in Carnoy's solution for $48 \mathrm{~h}$ and processed for paraffin embedding. Cross sections (6 $\mu$ m-thick) were obtained from embryos and testes and submitted to the labelling of DNMT1, DNMT3a 
and DNMT3b (see item 4.3). Five embryos from three different mothers were used for this analysis.

The male gonads of $16 \mathrm{dpc}$ embryos (20 embryos from 6 different mothers) were dissected and incubated with 5-Aza-2'-deoxicytidine (5-Aza-CdR) as described below (see item 4.2). The experiments were carried out under the rules of the local committee for animal care (CEUA Nr. 7,001,040,914).

\section{5-Aza-CdR Experiment}

The uterus of 18 pregnant females at gestation day 16 (GD16) were removed and taken to a culture room presterilised with UV light. The gonad cultures were performed according to Livera et al. [26] and Habert et al. [27]. The experiment was performed three times, using 6 dams for each experiment (total of 18 dams). A total of 72 male embryo gonads (24 gonads per experiment) were dissected and placed on gridded cellulose/ester membrane $(0.45 \mu \mathrm{m}$, HAWG047S0, Millipore, USA) in 24-well plates containing DMEM supplemented with GIBCO $^{\circ}$ GlutaMax (Life technologies), 0.5\% BSA, 1\% Penicillin/Streptomycin and $1 \mu \mathrm{M}, 3 \mu \mathrm{M}$ or $5 \mu \mathrm{M}$ of 5 Aza-CdR (InSolution ${ }^{\mathrm{Tm}}$, Cat. 189,826 - Calbiochem). These gonads are from here on referred as AzaC. Control culture $(\mathrm{CC})$ gonads were performed using the same culture medium except for the addition of 5-Aza-CdR. The cultures were maintained for 5 days. 5 -Aza-CdR was added on the 1st day of culture and replaced every day. The control and 5-Aza-CdR-treated gonad cultures were carried out concomitantly in every experiment, which was performed three times.

Six control and six 5-Aza-CdR-treated gonads (two from each experiment) were fixed in Carnoy's solution and embedded in paraffin for $5 \mathrm{mC}$ and $5 \mathrm{hmC}$ labelling and Haematoxilyn and Eosin (H\&E) staining. Other 30 control and 30 5-Aza-CdR-treated gonads (10 from each experiment) were used for PGC purification and RTPCR (see item 4.4). The gonads were dissected from 20 male embryos from 6 different mothers.

\section{Immunohistochemistry and Immunofluorescence}

The sections were dewaxed in xylene, hydrated and submitted to heat antigen retrieval using citrate buffer (pH 6.0) for 10 min (for DNMT1, DNMT3a, DNMT3b and $\mathrm{H} 3 \mathrm{~K} 27 \mathrm{me} 3)$ or to proteinase $\mathrm{K}(20 \mu \mathrm{g} / \mathrm{ml})$ for $5 \mathrm{~min}$ (for $5 \mathrm{mC}$ and $5 \mathrm{hmC}$ ). Antigen blocking was performed using 5\% BSA and the slides were incubated with primary antibodies: anti-5mC (1:50, Abcam, ab73938), anti-5hmC (1:50, Active Motif, 39,769), anti-DNMT1 (1:100, Santa Cruz, sc-20,701), anti-DNMT3a (1:100, Santa Cruz sc-20,703) anti-DNMT3b (1:100, Santa Cruz, sc-20,704), anti-Ki67 (Abcam, ab16667) and anti-DAZL (1:200, Serotec, MCA2336) overnight at $4{ }^{\circ} \mathrm{C}$. For immunohistochemistry the slides were washed in PBS (0.05 M, pH 7.2) and incubated with the LSAB system (DAKO Detection System - K0690) and then with streptavidin-peroxidase (LSAB, DAKO) for $30 \mathrm{~min}$. The reactions were revealed with $\mathrm{DAB}$ (DAKO). For immunofluorescence, after two PBS washes, the slides were incubated with the secondary antibodies Alexa (Invitrogen, A10036) anti-mouse and FITC (Abcam, Ab6791) anti-rabbit. The nuclei were stained with DAPI.

Because of protocol and antibody incompatibilities the double labelling of the methylation marks and PGC markers was not possible. Thus, germ cells were identified by their typical morphology (round nucleus and prominent nucleolus) and localization.

The slides were carefully analysed and the pattern of protein detection in germ cells was described using the Image Analysis System Leica QWin V3 (Cambridge, England) for immunohistochemistry and the NIS Element (Nikon) for immunofluorescence.

\section{PGC Quantification and Proliferation}

The Nv represents the number of cells in a given volume of tissue. PGC in the $\mathrm{CC}$ and $\mathrm{AzaC}$ gonads were counted and a numerical density (Nv) of these cells was obtained by the ratio between the number of PGC and the volume of the gonad tissue analysed (Zogbi et al. [46]). The quantification was performed in the Ki67/ DAZL double-stained gonads.

\section{Two-Step PGC Sorting and RT-PCR}

After 5 days in culture, the gonads were removed from the membrane dissociated in collagenase/dispase solution $\left(10,269,638,001\right.$, Roche) at $37{ }^{\circ} \mathrm{C}$, for $20 \mathrm{~min}$. The cell suspension was incubated for $2 \mathrm{~h}$ in 12-well plates pre-treated with gelatin (G1890, Sigma) for somatic cell adhesion. The medium containing non-adhered cells (including PGC) was centrifuged and resuspended in $1 \mathrm{X}$ PBS ( $\mathrm{pH}$ 7.2) containing magnetic beads pre-incubated with biotinilated Dolichus biflorus agglutinin (DBA). The suspension was incubated for $1 \mathrm{~h}$ at $4{ }^{\circ} \mathrm{C}$ rocking and placed in a magnetic rack (Invitrogen). The positive selected cells (PGC) and the negative selected cells (somatic cells) were submitted to RNA isolation using TRIzol $^{\circ}$ (Invitrogen). The cells that adhered to the 12well plates in the first step of the selection were treated with $1 \mathrm{X}$ trypsin (59418C, Sigma) and combined with the magnetic negative selection cells for RNA isolation. The cDNA was obtained using the Superscript III Reverse Transcriptase (Invitrogen). Conventional PCR was performed using specific primers for the developmental genes Pax6 (FP 5'-agtgaatgggcggagttatg-3' and RP 5' aacaaccacatgagccaaca- $3^{\prime}$ ) and Dazl (FP $5^{\prime}$-gaaatggcccacaaaagaaa- $3^{\prime}$ and $5^{\prime}$-ttaagcactgcccgacttct $-3^{\prime}$ ). 


\section{Acknowledgements}

The authors thank Fundação de Amparo à Pesquisa do Estado de São Paulo (FAPESP) for the financial support: Isabelle H. Cantão - 2012/25087-9), Renato B. Tesser - 2011/07078-0 and Taiza Stumpp - Proc. 2012/01024-8.

\section{Funding}

Fundação de Amparo à Pesquisa do Estado de São Paulo (FAPESP) - (Proc. Nr. 2012/01024-8, 2011/07078-0 and 2012/25087-9).

\section{Availability of Data and Materials}

Not applicable.

\section{Authors' Contributions}

IHC: execution of the work and writing; RBT: contribution with immunohistochemistry; TS: conception, design and writing. All authors read and approved the final manuscript.

\section{Ethics Approval and Consent to Participate}

The experiments were carried out under the rules of the local committee for animal care (CEUA Nr. 7,001,040,914).

\section{Consent for Publication}

Not applicable.

\section{Competing Interests}

The authors declare that they have no competing interests.

\section{Publisher's note}

Springer Nature remains neutral with regard to jurisdictional claims in published maps and institutional affiliations.

\section{Received: 11 May 2017 Accepted: 14 July 2017}

\section{Published online: 03 August 2017}

\section{References}

1. Lawson KA, Hage WJ. Clonal analysis of the origin of primordial germ cells in the mouse. CIBA Found Symp. 1994;182:68-84. discussion 84-91

2. Pesce $M$, Klinger $F G$, De Felici $M$. Derivation in culture of primordial germ cells from cells of the mouse epiblast: phenotypic induction and growth control by Bmp4 signalling. Mech Dev. 2002;112(1-2):15-24

3. Sato M, Kimura T, Kurokawa K, Fujita Y, Abe K, Masuhara M, Yasunaga T, Ryo A, Yamamoto M, Nakano T. Identification of PGC7, a new gene expressed specifically in preimplantation embryos and germ cells. Mech Dev. 2002; 113(1):91-4.

4. Saitou M. Germ cell specification in mice. Curr Opin Genet Dev. 2009;19(4): 386-95.

5. Ohinata Y, Payer B, O'Carroll D, Ancelin K, Ono Y, Sano M, Barton SC, Obukhanych T, Nussenzweig M, Tarakhovsky A, Saitou M, Surani MA. Blimp1 is a critical determinant of the germ cell lineage in mice. Nature. 2005; 436(7048):207-13.

6. Vincent SD, Dunn NR, Sciammas R, Shapiro-Shalef M, Davis MM, Calame K, Bikoff EK, Robertson EJ. The zinc finger transcriptional repressor Blimp1/ Prdm1 is dispensable for early axis formation but is required for specification of primordial germ cells in the mouse. Development. 2005; 132(6):1315-25.

7. Lange UC, Saitou M, Western PS, Barton SC, Surani MA. The fragilis interferon-inducible gene family of transmembrane proteins is associated with germ cell specification in mice. BMC Dev Biol. 2003;3:1.

8. Guibert S, Forné T, Weber M. Global profiling of DNA methylation erasure in mouse primordial germ cells. Genome Res. 2012;22(4):633-41.

9. Seki Y, Hayashi K, Itoh K, Mizugaki M, Saitou M, Matsui Y. Extensive and orderly reprogramming of genome-wide chromatin modifications associated with specification andearly development of germ cells in mice. Dev Biol. 2005;278(2):440-58

10. Hajkova P, Erhardt S, Lane N, Haaf T, El-Maarri O, Reik W, Walter J, Surani MA. Epigenetic reprogramming in mouse primordial germ cells. Mech Dev. 2002;117(1-2):15-23.

11. Kobayashi H, Sakurai T, Miura F, Imai M. Mochiduki K, Yanagisawa E, Sakashita A, Wakai T, Suzuki Y, Ito T, Matsui Y, Kono T. High-resolution DNA methylome analysis of primordial germ cells identifies gender-specific reprogramming in mice. Genome Res. 2013;23(4):616-27.
12. Hackett JA, Reddington JP, Nestor CE, Dunican DS, Branco MR, Reichmann J, Reik W, Surani MA, Adams IR, Meehan RR. Promoter DNA methylation couples genome-defence mechanisms to epigenetic reprogramming in the mouse germline. Development. 2012;139(19):3623-32.

13. Seisenberger $S$, Andrews $S$, Krueger $F$, et al. The dynamics of genome-wide DNA Methylation reprogramming in mouse primordial germ cells. Mol Cell. 2012;48(6):849-62.

14. Popp C, Dean W, Feng S, Cokus SJ, Andrews S, Pellegrini M, Jacobsen SE, Reik W. Genome-wide erasure of DNA methylation in mouse primordial germ cells is affected by AID deficiency. Nature. 2010;463(7284):1101-5.

15. Seki Y, Yamaji M, Yabuta Y, Sano M, Shigeta M, Matsui Y, Saga Y, Tachibana M, Shinkai Y, Saitou M. Cellular dynamics associated with the genome-wide epigenetic reprogramming in migrating primordial germ cellsin mice. Development. 2007;134(14):2627-38.

16. Hackett JA, Surani MA. DNA methylation dynamics during the mammalian life cycle. Philos Trans R Soc Lond Ser B Biol Sci. 2013;368(1609):20110328.

17. Yamaguchi S, Hong K, Liu R, Inoue A, Shen L, Zhang K, Zhang Y. Dynamics of 5-methylcytosine and 5-hydroxymethylcytosine during germ cell reprogramming. Cell Res. 2013;23(3):329-39.

18. La Salle S, Mertineit C, Taketo T, Moens PB, Bestor TH, Trasler JM. Windows for sex-specific methylation marked by DNAmethyltransferase expression profiles in mouse germ cells. Dev Biol. 2004;268(2):403-15.

19. Sakai Y, Suetake I, Itoh K, Mizugaki M, Tajima S, Yamashina S. Expression of DNA Methyltransferase (Dnmt1) in testicular germ cells during development of mouse embryo. Cell Struct Funct. 2001;26:685-91.

20. Kelly TL, Trasler JM. Reproductive epigenetics. Clin Genet. 2004;65(4):247-60.

21. Hackett JA, Zylicz JJ, Surani MA. Parallel mechanisms of epigenetic reprogramming in the germline. Trends Genet. 2012;28(4):164-74.

22. Ramos MP, Wijetunga NA, AS ML, Suzuki M, Greally JM. DNA demethylation by 5-aza-2'-deoxycytidine is imprinted, targeted to euchromatin, and has limited transcriptional consequences. Epigenetics Chromatin. 2015 Mar 17;8:11.

23. Yamagata Y, Szabó P, Szüts D, Bacquet C, Arànyi T, Páldi A. Rapid turnover of DNA methylation in human cells. Epigenetics. 2012 Feb;7(2):141-5.

24. Chik F, Szyf M. Effects of specific DNMT gene depletion on cancer cell transformation and breast cancer cell invasion; toward selective DNMT inhibitors. Carcinogenesis. 2011 Feb;32(2):224-32.

25. Encinas G, Zogbi C, Stumpp T. Detection of four germ cell markers in rats during testis morphogenesis: differences and similarities with mice. Cells Tissues Organs. 2012;195(5):443-55.

26. Livera G, Delbes G, Pairault C, Rouiller-Fabre V, Habert R. Organotypic culture, a powerful model for studying rat and mouse fetal testis development. Cell Tissue Res. 2006 Jun;324(3):507-21.

27. Habert R, Devif I, Gangnerau MN, Lecerf L. Ontogenesis of the in vitro response of rat testis to gonadotropin-releasing hormone. Mol Cell Endocrinol. 1991 Dec;82(2-3):199-206.

28. Davidson S, Crowther P, Radley J, Woodcock D. Cytotoxicity of 5-aza-2'deoxycytidine in a mammalian cell system. Eur J Cancer. 1992;28(2-3):362-8.

29. Okano M, Bell DW, Haber DA, Li E. DNA methyltransferases Dnmt3a and Dnmt3b are essential for de novo methylation and mammalian development. Cell. 1999 Oct 29;99(3):247-57.

30. Takeshima H, Suetake I, Shimahara H, Ura K, Tate S, Tajima S. Distinct DNA methylation activity of Dnmt3a and Dnmt3b towards naked and nucleosomal DNA. J Biochem. 2006 Mar:139(3):503-15.

31. Rose CM, van den Driesche S, Sharpe RM, Meehan RR, Drake AJ. Dynamic changes in DNA modification states during late gestation male germ line development in the rat. Epigenetics Chromatin. 2014;7:19.

32. Zogbi C, Tesser RB, Encinas G, Miraglia SM, Stumpp T. Gonocyte development in rats: proliferation, distribution and death revisited. Histochem Cell Biol. 2012 Aug;138(2):305-22.

33. Sachs M, Onodera C, Blaschke K, Ebata KT, Song JS, Ramalho-Santos M. Bivalent chromatin marks developmental regulatorygenes in the mouse embryonic germline in vivo. Cell Rep. 2013;3(6):1777-84.

34. Bernstein BE, Mikkelsen TS, Xie X, Kamal M, Huebert DJ, Cuff J, Fry B, Meissner A, Wernig M, Plath K, Jaenisch R, Wagschal A, Feil R, Schreiber SL, Lander ES. A bivalent chromatin structure marks key developmental genes in embryonic stem cells. Cell. 2006;125(2):315-26.

35. Lim DH, Maher ER. Genomic imprinting syndromes and cancer. Adv Genet. 2010;70:145-75

36. Messerschmidt DM, Knowles BB, Solter D. DNA methylation dynamics during epigenetic reprogramming in the germline and preimplantation embryos. Genes Dev. 2014;28(8):812-28. 
37. La Salle S, Trasler JM. Dynamic expression of DNMT3a and DNMT3b isoforms during male germ cell development in the mouse. Dev Biol. 2006; 296(1):71-82.

38. He X-J, Chen T, Zhu J-K. Regulation and function of DNA methylation in plants and animals. Cell Res. 2011;21(3):442-65.

39. Palii SS, Van Emburgh BO, Sankpal UT, Brown KD, Robertson KD. DNA methylation inhibitor 5-Aza-2'-deoxycytidine induces reversible genomewide DNA damage that is distinctly influenced by DNA methyltransferases 1 and 3B. Mol Cell Biol. 2008 Jan;28(2):752-71.

40. Oka M, Meacham AM, Hamazaki T, Rodić N, Chang $\sqcup$, Terada N. De novo DNA methyltransferases Dnmt3a and Dnmt3b primarily mediate the cytotoxic effect of 5-aza-2'-deoxycytidine. Oncogene. 2005 Apr 28;24(19):3091-9.

41. Chen T, Ueda Y, Dodge JE, Wang Z, Li E. Establishment and maintenance of genomic methylation patterns in mouse embryonic stem cells by Dnmt3a and Dnmt3b. Mol Cell Biol. 2003;23(16):5594-605.

42. Pawlak M, Jaenisch R. De novo DNA methylation by Dnmt3a and Dnmt3b is dispensable for nuclear reprogramming of somatic cells to a pluripotent state. Genes Dev. 2011;25(10):1035-40.

43. Kato Y, Kaneda M, Hata K, Kumaki K, Hisano M, Kohara Y, Okano M, Li E, Nozaki M. SasakiH.Role of the Dnmt3 family in de novo methylation of imprinted and repetitive sequences during male germ cell development in the mouse. Hum Mol Genet. 2007:16(19):2272-80.

44. Kurimoto K, Yabuta Y, Ohinata Y, Shigeta M, Yamanaka K, Saitou M. Complex genome-wide transcription dynamics orchestrated by Blimp 1 for the specification of the germ celllineage in mice. Genes Dev. 2008;22(12): 1617-35.

45. Salem CE, Markl ID, Bender CM, Gonzales FA, Jones PA, Liang G. PAX6 methylation and ectopic expression in human tumor cells. Int J Cancer. 2000;87(2):179-85.

46. Schmidt CS, Bultmann S, Meilinger D, Zacher B, Tresch A, Maier KC, Peter C, Martin DE, Leonhardt H, Spada F. Global DNA hypomethylation prevents consolidation of differentiation programs and allows reversion to the embryonic stem cell state. PLoS One. 2012;7(12):e52629.

\section{Submit your next manuscript to BioMed Central and we will help you at every step:}

- We accept pre-submission inquiries

- Our selector tool helps you to find the most relevant journal

- We provide round the clock customer support

- Convenient online submission

- Thorough peer review

- Inclusion in PubMed and all major indexing services

- Maximum visibility for your research

Submit your manuscript at www.biomedcentral.com/submit

) Biomed Central 